\title{
Mangroves of Vietnam: historical development, current state of research and future threats
}

\author{
Bijeesh KozhikkodanVeettil ${ }^{\text {ab }}$ Raymond D.Ward ${ }^{\text {cd }}$ Ngo XuanQuang ${ }^{\text {ef }}$ Ngo Thi
}

ThuTrang ${ }^{\mathrm{g}}$ Tran HoaiGiang ${ }^{\mathrm{h}}$

A Department for Management of Science and Technology Development, Ton Duc Thang University, Ho Chi Minh City, Vietnam

B Faculty of Environment and Labour Safety, Ton Duc Thang University, Ho Chi Minh City, Vietnam

C Centre for Aquatic Environments, School of the Environment and Technology, University of Brighton, Cockcroft Building, Moulsecoomb, Brighton, BN2 4GJ, United Kingdom

D Institute of Agriculture and Environmental Sciences, Estonian University of Life Sciences, Kreutzwaldi 5, EE-51014, Tartu, Estonia

E Department of Environmental Management and Technology, Institute of Tropical Biology, Vietnam Academy of Science and Technology, Ho Chi Minh City, Vietnam F Graduate University of Science and Technology, Vietnam Academy of Science and Technology, Hanoi, Vietnam

G Department of Geography, University of Social Sciences and Humanities, VNUHCM, Ho Chi Minh City, Vietnam

H Southern Sub-Institute of Fisheries Economics and Planning, Ho Chi Minh City, Vietnam

ABSTRACT: Vietnamese mangroves are among the most productive \& biologically important ecosystems of the world; providing habitat/nursing grounds for commercial \& non-commercial fish species, food, medicine, building materials/fuel for local communities, as well as carbon storage (blue carbon) \& coastal protection from storm events. However, Vietnam's mangroves have been lost in recent decades $(\sim 38 \%)$ or degraded, predominantly driven by herbicides during the Vietnam War and later by conversion to aquaculture and coastal development, although there has been a recent slowing of this degradation as a result of restoration and protection schemes. In this review article, the current state of mangrove ecosystems in Vietnam, their evolution and restoration efforts are discussed in detail as well as highlighting challenges to management and rehabilitation schemes. Further discussion includes the socio- 
economic benefits derived from mangroves in Vietnam as well as recent developments in research with reference to major mangrove forests (Can Gio, Ca Mau and Red River Delta) in the country. Special attention is given to recent studies using remote sensing techniques, including advantages and future challenges, in mangrove research focussing on Vietnamese mangroves. The impacts of climate change are discussed and evaluated with a particular focus on sea level rise and changes to sediment budgets as a result of the increase in hydropower station on major river course.

\section{Introduction}

The term mangrove is not applied to a specific plant species but to a wide variety of trees and shrubs (roughly around 80 species worldwide) adapted to extreme conditions such as high salinity, low oxygen content and changing water levels (Saenger et al., 1983). These ecosystems dominate low energy tropical and subtropical coastlines between $32^{\circ} \mathrm{N}$ and $38^{\circ} \mathrm{S}$ (Brander et al., 2012). The distribution of mangroves, however, is highly dependent on temperature (minimum, annual average and frost events) and moisture (Kathiresan and Bingham, 2001). The global distribution of mangrove vegetation is shown in Fig. 1 (Spalding et al., 2010). Mangrove communities are mostly, dominated by four genera: Rhizophora, Bruguiera, Sonneratia, and Avicennia (Bann, 1998) and are considered as world's most productive ecosystems (Kathiresan and Bingham, 2001).

Fig. 1: Global distribution of mangrove vegetation (Source: Giri et al., 2011)

\section{Mangrove ecosystem along the Vietnamese coastline}



located in the south and north are typically more extensive than those in central Vietnam. The predominantly rocky coastline of central Vietnam means that mangroves in this region are limited to a narrow strip within estuaries. Lower temperatures in the North have been suggested to influence the biodiversity of the mangroves located there (FAO 2005).

66 2011). in Southeast Asia (Brander et al., 2012) the majority is in Indonesia and has been covered by various reviews (e.g. Alongi, 2008, 2015). However, the $3260 \mathrm{~km}$ long coastline of Vietnam also accounts for a substantial proportion, supporting mangroves with high ecological and economic importance also playing an important role in environmental protection (Le, 2008). Two globally important river deltas are located here - Red River Delta in the north and Mekong River Delta in the south, and they have extensive associated mangrove ecosystems. It has been estimated that mangrove forests in Vietnam covered an area of 400,000 ha prior to the Vietnam War (Maurand, 1943) and the use of herbicides and napalm during the war destroyed more than 100,000 ha of mangrove forest (Hong and San, 1993). Spalding et al. (1997) observed that the remaining mangrove vegetation in the Vietnamese coastlines consists mostly of secondary communities and that degraded soils limited regeneration of new vegetation. Further loss of mangrove forest during the post-war period has occurred due to the creation of shrimp ponds, salt ponds and paddy cultivation (Hong and San, 1993). Graaf and Xuan (1998) reported a loss of nearly $23 \%$ of mangrove vegetation during the 
period 1977-1995 due to extensive and unsustainable shrimp farming. Out of the 400,000 ha mangrove area estimated by Maurand (1943) before the Vietnam War, 200,000 ha were located in the Ca Mau Peninsula (Moquillon, 1950) and 40,000 ha in Rung Sat-Bien Hoa province and Ho Chi Minh City (Saigon) area (Cuong, 1964). Early studies on mangroves in Vietnam after the war can be found in NAS (1974), Ross (1975) and Teas and Kelly (1975) who investigated the impacts of herbicides such as Agent Orange and Agent White on mangrove forests in the south during the Vietnam War. The total area occupied by mangroves in Vietnamese coastlines based on 1977 World Mangrove Atlas from relevant studies (Field, 1996; Spalding et al., 1997; Blasco et al., 1998) was about 220,000 ha. Other figures have been suggested including 250,000 ha (IUCN, 1983), 252,500 ha according to the Forest Inventory and Planning Institute of Vietnam (Hong and San, 1993). Blasco et al. (2001) presented a mangrove inventory for Vietnam (in the Mekong Delta) using satellite imagery (1997/98) with a total area of 210,000 ha, of which 80,000 ha were identified as degraded areas and 130,000 ha reafforested areas. Rhizophora and Avicennia are the most commonly occurring mangrove genera in Vietnam (Chapman, 1984).

Mangrove forests in Vietnam can be divided into four zones (Hong, 1984, 1991): Zone 1 (northeast) between Ngoc cape to Do Son cape with an area of 39,400 ha; zone 2 (northern delta) from Do Son cape to Lach River mouth (7,000 ha); zone 3 (central coast) from the Lach river mouth to $\mathrm{Vu}$ Tau cape with a 14,300 ha mangrove forests; zone 4 (coast of southern Vietnam) between Vung Tau Cape and Ha Tien covered 191,800 ha, and is the largest and richest mangrove ecosystem in Vietnam. It has to be noted that the flora and fauna associated with mangrove ecosystems and mangrove species itself may vary in these four zones in Vietnam (Hong and San, 1993). Coverage of mangrove vegetation in the four zones mentioned above is shown in Fig. 3. 
110 Northeastern coast of Vietnam (zone 1) has suitable environmental conditions for 111 mangrove ecosystems (Hong, 1984, 1991). However, climate conditions during the 112 winter in zone 1 are strongly influenced by the northeast monsoon and low air 113 temperatures, which limit mangrove growth. The northern delta (zone 2) has suitable 114 soil and hydrological conditions for mangrove vegetation, mainly due to the alluvial 115 deposits from the Hong and Thai Binh rivers, although this area is susceptible to strong winds and tidal currents (Hong and San, 1993). Zone 3 (central coast) has a non-planar

117 coast, less fertile soils than other areas, and is influenced by strong winds, water currents and frequent storms resulting in the least favourable conditions for mangrove forests (Hong, 1984, 1991; Hong and San, 1993). The southern coast of Vietnam (zone 4) has the most favourable conditions for mangrove ecosystems with a low lying topography, abundant nutrient-rich alluvial deposits (mainly by Cuu Long and Dong Nai rivers) and hydrology, few storms and weaker water currents (Hong and San, 1993; Loon et al., 2007).

Fig. 3: Mangrove distribution in four different zones in Vietnam (after Hong, 1984)

\section{Holocene development of major estuaries and deltas in Vietnam} in Vietnam, can be dated to between $\sim 8 \mathrm{ka}$ BP (period of maximum flooding) to $4.8 \mathrm{ka}$ BP (sea level high stand) as a result of marine transgression (Nguyen et al., 2000; Hannebuth et al., 2012). The most significant of these are the Red River and Mekong, two of the largest deltas in South East Asia, located in the north and south of the country respectively. These two large deltas underwent a transformation from predominantly estuarine to deltaic roughly $8.5 \mathrm{ka}$ BP (Red River) and 4.6ka BP 
(Mekong) (Hori et al., 2004; Funabiki et al., 2007; Hannebuth et al., 2012). Following this, progradation and subsequent formation of intertidal mudflats and mangrove

137 colonisation took place in areas formerly inundated by the sea (Hannebuth et al., 2012) and both of these large deltas altered from a tidally dominated estuarine setting to a wave dominated open coast setting (Nguyen et al., 2000; Tanabe et al., 2006; Tamura et al., 2009). This progradation has been as a result of the high sediment loads estimated to have been carried by both the Red River delta and the Mekong over the last 3ka (Ta et al., 2002). In the Red River delta, progradation has rapidly increased over the last $2 \mathrm{ka}$ $\mathrm{BP}$, in part as a result of anthropogenically driven land cover change (deforestation and conversion to agriculture). This has resulted in increases in sediment discharge from 17-27 (9-2 cal. ka BP) to 49 million t/yr (2-0 cal. ka BP)(Tanabe et al., 2006), similar to patterns described in other parts of Asia including Huanghe (Yellow River) delta 147 (Saito et al., 2001) and Changjiang (Yangtze) (Hori et al., 2001, 2002a, 2002b). In the Mekong however, sediment discharges have remained stable and high over the last $3 \mathrm{ka}$ ( $144 \pm 36$ million $\mathrm{t} / \mathrm{yr}$ ) resulting in delta progradation of ca $200 \mathrm{~km}$ over the last $6-7 \mathrm{ka}$ (Ta et al., 2002) and the subaqueous delta between 250-300 $\mathrm{km}$ over this time period (Liu et al., 2017).

152

\section{Environmental factors influencing mangrove ecosystems in Vietnam}

Hong and San (1993) discussed a number of factors influencing mangrove distribution and structure in Vietnam: climate (temperature, rainfall, and wind), hydrology (tides, ocean currents, freshwater currents, salinity, and erosion in coastal areas), soil and topography. In addition to these factors, a number of anthropogenic activities have been played a key role in the fragmentation of mangrove forests in Vietnam. Furthermore, mangrove ecosystems in Vietnam are also under threat due to global sea level rise 
five main causes of mangrove loss in Vietnam: (1) non-sustainable use of mangrove ecosystems for aquaculture, (2) storms, waves and natural disasters, (3) deforestation of mangrove forests for timber and natural resources, (4) multi-source pollutants from agriculture and urban areas, (5) lack of sufficient regulatory mechanisms for the protection and sustainable development of mangrove ecosystems (Tuan and Kuenzer, 2012). Tuan and Kuenzer (2012) also observed additional causes such as increasing population density and urban growth combined with illegal logging. River in Vietnam undergone a $76 \%$ reduction in fluvial sediment loads entering the coastal zone due to river modification and damming (Gupta et al., 2012), which may cause a sediment deficit for mangroves (Ward et al., 2016a). Even though mangroves can survive on a wide variety of soils, they typically grow better in silt-clay soils, which are abundant on the coast of Vietnam (Hong and San, 1993). Other than the physical characteristics, chemical composition (minerals and organic matter, $\mathrm{pH}$ ) of soil also play an important role in mangrove distribution (Cahoon et al., 2006). Topography highly influences mangrove distribution because this factor influences wave activity (Alongi, 2008; Ward et al., 2016a).

Anthropogenic factors require special attention considering the present conditions of mangrove fragmentation and loss in the Vietnamese coast, and Mekong Delta in general. Herbicides applied during the Vietnam War had a serious negative influence on mangrove growth in the country (Ross, 1975). Activities such as exploiting mangrove areas for shrimp farming and timber have a direct impact on the ecosystem and are highly visible. However, there are some factors that cannot not be distinguished as a result of natural or anthropogenic forcings (Lewis et al., 2011). Le et al. (2007) 
observed the possibility of a combined impact on flooding due to sea level rise, agricultural activities, and manmade structures (such as dams and settlements) in the Mekong delta resulting in mangrove submergence and migration inland. Lateral migration of mangroves inland is affected by anthropogenic barriers such as hard infrastructure (Ward et al., 2016a). Other anthropogenic factors affecting mangrove ecosystems are waste disposal (containing trace metals, organic contaminants and chemicals from urban, industrial and agricultural areas) and oil spills (Lewis et al., 2011; Bayen, 2012), which can exceed physiological tolerances of mangroves (Tam et al., 2005). A few notable studies were conducted on mangrove ecosystem/habitat in Vietnam that observed complex organic materials (Kishida et al., 2010), antibiotics (Le and Munekage, 2004), sedimentary organic carbon (Tue et al., 2010), insecticides (Thao et al., 1993), and Dioxin contamination in the soil (Dwernychuk et al., 2002; Mai et al., 2007) resulting in degradation.

\section{Sedimentary and hydrological environment in mangroves in Vietnam}

The majority of mangroves in Vietnam grow on silty-clay soils which are common along the estuarine, deltaic and bay coasts of Vietnam, ideal for mangrove growth. In the north of the country some mangrove soils are comprised of alluvium derived from lateritic hill soils and on islands in Ha Long and Bai Tu Long Bays soils are derived from limestone sediments. Sediment dynamics are quite variable along the coast of Vietnam with large-scale sediment discharge in the prograding deltas of the Red River and Mekong and much smaller scale in the centre of the country where the coast runs parallel to the Truong Son range. The rapid progradation of the Mekong delta provides an excellent location for the establishment of mangroves, with some areas experiencing progradation rates of $60 \mathrm{~m} / \mathrm{yr}$ (south west), whilst others have experienced 
little or no progradation (northeast) in recent decades (Nardin et al., 2016) resulting in asymmetric progradation (Fricke et al., 2017). This is related to the interaction by waves, fluvial sediment supply, tides and subsidence (average $1.6 \mathrm{~cm} / \mathrm{yr}$ but can be as high as $4 \mathrm{~cm} / \mathrm{yr}$, Erban et al., 2014) all of which are spatially variable. In the Mekong delta there appears to be limited sediment deposition within major channels, which are considered to be relatively stable over ka timescales, predominantly due to flushing during periods of high discharge (Allison et al., 2017a), meaning the majority of the sediment deposited is outside of the channels in shallow water areas including mudflats and mangrove areas (Eidam et al., 2017). Sediment deposition within the Mekong delta varies greatly as a result of tidal influences, increased stratification in the water column as a result of neap tides in the estuarine reaches leads to a $50 \%$ reduction in suspended sediment concentration compared with spring tides resulting in lower sediment accumulation rates during neaps (Fricke et al., 2017) and suspended sediment concentrations are highest in the offshore plumes of the Mekong delta consistent with the intrusion of a salt wedge (Wackerman et al., 2017). In the Mekong delta sediment continue in mangroves as a result of waves and currents redistributing sediment deposited during the high discharge season (Tamura et al., 2010; McLachlan et al., 2017; Stephens et al., 2017; Thanh et al., 2017). The foreshore of the Mekong delta is a highly dynamic system with spatio-temporal variation in accretion and erosion in some cases extreme erosion (up to $30 \mathrm{~m} / \mathrm{yr}$ ) followed by massive accretion ( $\sim 0.05 \mathrm{~m}$ over four tidal cycles) (Anthony et al., 2017) and similar dynamics have also been reported for the Red River delta (van Maren, 2007). In the Mekong delta, cross shore tidal currents rapidly decrease in velocity as they reach fringing mangroves then stay fairly consistent 
over the outer few $100 \mathrm{~m}$ resulting in high deposition rates in these areas (Bryan et al., 2017).

Progradation rates at the Song Hau mouth in the Mekong delta have been reported as $11-13 \mathrm{~m} / \mathrm{yr}$ and further south at Cape Ca Mau as high as $26 \mathrm{~m} / \mathrm{yr}$ (Xue et al., 2010), with nearshore sediment accumulation rates between $1-3 \mathrm{~cm} / \mathrm{yr}$ over the last 100 yrs (De Master et al., 2017), although this is highly spatially variable and sediment accumulation can be as high as $10 \mathrm{~cm} / \mathrm{yr}$ over the last 100 years (Unverricht et al., 2013). Sonneratia pneumatophores in the Mekong delta have been shown to provide a spatial control over sediment accumulation with recent studies showing that trees increase bottom drag (Henderson et al., 2017; Mullarney et al., 2017), and rates of turbulent kinetic energy (Norris et al., 2017), slowing water velocity and facilitating initial sedimentation (Bullock et al., 2017) and promoting sediment deposition (Van Santen et al., 2007; Fagherazzi et al., 2017) or at the very least retention of the flood tide sediment influx (Phuoc and Massel, 2006). Similar results have been reported for Kandelia candel mangroves in the Red River delta (Quartel et al., 2007). Fringing mangrove sediments in the Mekong delta are more sandy at the edge and fining with distance into the mangrove (Norris et al., 2017) predominantly as a result of decreases in velocity and thus sediment carrying capacity, as has been reported for other areas (Mazda et al., 2005; Vo-Luong and Massel, 2008; Suzuki et al., 2012). Schwarzer et al. (2016) reported that whilst sediment movement in the Mekong delta was predominantly driven by tide induced currents, tropical rainfall at low tide can also play a significant role in sediment redeposition and during heavy rainfall events can result in greater sediment transport in higher elevation mangrove areas than tidal currents. Sediment accumulation rates also vary greatly both spatially and temporally, with rates varying from $5.1 \mathrm{~cm} / \mathrm{yr}$ in the forest interior and $3 \mathrm{~cm} / \mathrm{yr}$ at the fringe derived from ${ }^{210} \mathrm{~Pb}$ dating in Mekong delta 
mangroves (Fricke et al., 2017). At times sediment accretion rates in the Mekong delta can be so high as to smother mangrove roots resulting in forest dieback (Fagherazzi et al., 2017). In fringing mangroves where elevation above m.s.l. becomes high enough as a result of sediment accumulation other species colonise resulting in pioneer species dieback and replacement (Bullock et al., 2017). In addition to monsoonal variation influencing sediment discharge, the El Niño-Southern Oscillation has been found to have an effect in the Mekong delta with greater sediment discharge and a longer annual flood period recorded during La Niña events (Räsänen and Kammu, 2013). area of brackish water influence as far inland as Cao Lanh $130 \mathrm{~km}$ upstream, and typically sediments are much finer closer to the seaward end of the delta (Gugliotta et al., 2017). Since the 1990's there has been a substantial increase in hydropower development in Vietnam (Cochrane et al., 2014), which has resulted in a dramatic decrease in sediment discharge in the Mekong delta (Milliman and Farnsworth, 2011). Estimates of sediment discharge following dam completion in the 90's, range from 67 to 145 million tonnes/yr (Wang et al., 2011; Koehnken, 2014; Liu et al., 2013; Lu et al., 2015) down from 160 million tonnes/yr prior to dam construction (Wild and Loucks, 2014). This has had a substantial impact on the sediment regime and eroded shorelines have increased from $44 \%$ pre dam construction to $66 \%$ post dam construction, and although most shorelines in the estuarine area are still accreting, sediment discharge continues to decrease ( $\mathrm{Li}$ et al., 2017).

\section{Important mangrove areas in Vietnam}

\subsection{Can Gio mangrove biosphere reserve}



in Vietnam by UNESCO), including terrestrial and marine, has a surface area of 75,740 ha situated in Can Gio district of Ho Chi Minh City $\left(10^{\circ} 22^{\prime} 14^{\prime \prime}-10^{\circ} 40^{\prime} 09^{\prime \prime} \mathrm{N}\right.$; $106^{\circ} 46^{\prime} 12^{\prime \prime}-107^{\circ} 00^{\prime} 59^{\prime \prime}$ E) (Nam et al., 2014). The core area of this mangrove reserve is only 4,721 ha and transitional zones and buffer zones occupy 29,880 ha and 41,139 ha respectively and no communities live in the core area and buffer zone of this region (UNESO, 2015a). The soil foundation for this mangrove forest is created by the Saigon and Dong Nai rivers. Le (2008) estimated tidal effects from the China Sea, Saigon and Don Nai rivers on the hydrological regime of the Can Gio mangrove forests and observed that averages of high and low tides were higher in the dry season than in the wet season. The same study also observed that flooding frequency and elevation of the study sites affected primary production and species distribution in Can Gio. UNESCO (2015a) estimated that about 28,130 ha of mangroves (planted: 21,104 ha; natural: 7,026 ha) and 11,087 ha of non-mangrove vegetation existed in Can Gio in 1999. Three main mangrove species found in this region are Rhizophora apiculata, Acanthus ebracteatus, and Thespesia populnea. Loon et al. (2007) classified Can Gio mangroves into five classes based on tidal regimes: high tidal areas (no mangroves observed), medium high tidal areas (Avicennia spp., Sonneratia), normal high tidal areas (Rhizophora spp., aureum), and equinoctial tidal areas (Ceriops spp., Phoenix paludosa). Tuan and Kuenzer (2012) evaluated the current status, dynamics and ecosystem services of the Can Gio mangrove biosphere reserve and presented a very detailed report. Recently, 306 Kuenzer and Tuan (2013) assessed the entire ecosystem service value of the same region by using both household surveys and satellite data. Both the studies observed the major threats to Can Gio mangrove biosphere as shoreline erosion due to ships, 
expansion of aquaculture and salt farming, and illegal timber extraction. Can Gio mangroves are also vulnerable to typhoons (Diele et al., 2013) and lightning strikes

311 (Kauts et al., 2011) although some studies have contradicted the suggestion that lightning impacts Can Gio mangroves (e.g. Ong and Gong, 2013). Based on a study in 10 sites in Can Gio, Nam and Tri (2014) observed that the overall erosion rate between 1953 and 2010 was very high (89.9 ha/year) compared to the overall progradation rate (5.5 ha/year). Fig.4 shows the evolution of mangrove forests in Can Gio district, southern Vietnam between the post-Vietnam War periods and present. Major mangrove species planted in Can Gio mangrove areas (1978-2000) are: Rhizophora apiculata (21,100 ha), Ceriops spp. (638 ha), and Nypa fruticans (281 ha) (Nam and Sinh, 2015).

Fig. 4: Defoliation of Can Gio mangroves soon after the Vietnam War in 1973 (Landsat MSS) and in 2017 January (Landsat OLI). 1973 image shows defoliation due to herbicides applied during the war and 2017 image shows regenerated (and reforested) areas in red.

\subsection{Mangrove forests in Ca Mau Peninsula}

The Ca Mau mangrove ecosystem $\left(8^{\circ} 32^{\prime}-8^{\circ} 49^{\prime} \mathrm{N}, 104^{\circ} 40^{\prime}-105^{\circ} 19^{\prime} \mathrm{E}\right)$ is situated on a lowland deltaic plain at the southern tip of Vietnam and has a dense network of canals (Hong and San, 1993). Like Can Gio mangroves, Ca Mau mangroves

(Fig. 5) were also affected by herbicides during the war (Ross, 1975) and regenerated (and reforested) later. Hong and San (1993) reported that about 56\% of the mangrove area was destroyed during the Vietnam War. The Ca Mau mangrove ecosystem is influenced by erosion along the East Sea (erosion rate: $33.24 \mathrm{~m} /$ year) and progradation along the Gulf of Thailand (progradation rate: $40.65 \mathrm{~m} /$ year) (Thi et al., 2014). The loss 
of mangroves in $\mathrm{Ca}$ Mau region is reported to have caused by intensive aquaculture

335 (Hashimoto, 2001) and the construction of numerous dams in the Mekong as well, due 336 to deforestation and reduction of sediment supply (Thi et al., 2014). Dominant

337 mangrove species found in this region are Avicennia alba, A. marina, A. officinalis, 338 Rhizophora parviflora, Brugueira parviflora, Ceriops zippeliana, and Nypa fruticans 339 (Hung and Tan, 1999; Masso i Alemano et al., 2010). A recent study by Thi et al. 340 (2014) showed that erosion rates along the east sea varied between $10.28 \mathrm{~m} /$ year to $34138.31 \mathrm{~m} /$ year during the period $1953-2011$, which is very high compared to other areas 342 in Vietnam. Koedam et al. (2007) suggested that Ca Mau mangroves cannot be compared with any other mangrove ecosystems in the world due to their dynamic nature.

Fig. 5: Mangroves of Ca Mau Peninsula (after Spalding et al., 2010)

In addition to the loss of mangroves due to timber cutting, aquaculture expansion has also caused a major loss of mangroves in Ca Mau (Giesen et al., 2006; Binh et al., 2005), particularly in the 1980s (Hong and San, 1993). The construction of hydroelectric dams and irrigation canals can impact mangrove ecosystems due to altered erosion or accretion rates (Hashimoto, 2001). The presence of dams may periodically increase (Koedam and Dahdouh-Guebas, 2008) or decrease (Ellison and Zouh, 2012) water volume and sediment transport to the mangrove ecosystems depending on the region and the most likely scenario for Mekong River is observed to be the latter one 356 (Thi et al., 2014). Lu and Siew (2006) observed that monthly suspended sediment concentration has decreased by up to $30 \%$ at some recording stations. 


\subsection{Mangrove forests in the Red River (Song Hong) Delta region}

The Red River Delta $\left(20^{\circ} 00^{\prime}-21^{\circ} 04^{\prime} \mathrm{N}, 106^{\circ} 01^{\prime}-107^{\circ} 08^{\prime}\right.$ E) is densely populated and agricultural activities (mostly rice cultivation) are intensive in this area. This region was designated as the Red River Delta Biosphere Reserve as a part of the Man and Biosphere Programme by UNESCO in 2004 (UNESCO, 2015b). Mangroves in the intertidal area of this region (Fig. 6) belong to Zone 2, discussed earlier. This region is globally important due to the appearance of several migratory bird species (Pedersen et al., 1998), even though species diversity is lower compared to southern mangrove areas in Vietnam (Pedersen and Nguyen, 1996). The regional importance of mangroves in the Red River Delta is due to the ecosystem services (coastal protection and biodiversity in particular) they provide. Furthermore, mangrove forests provide biomass fuel, raw materials for traditional medicines (Osbeck et al., 2010) and support local production of foodstuffs such as honey (Pedersen and Nguyen, 1996). There are about 26 mangrove species are found here and the dominant tree species are Kandelia candel, Sonneratia caseolaris (UNESCO, 2015b), Bruguiera gymnorhiza, and Aegiceras corniculatum (Tue et al., 2011). Pham and Yoshino (2016a), using ALOS-2 PALSAR data, estimated a total mangrove area of 4084 ha in Hai Phong district in 2015 (K. obovata: 265 ha, S. caseolaris: 2781 ha, mixed species: 1046 ha).

Fig. 6: Mangroves of the Red River Delta (after Spalding et al., 2010)

The population in this deltaic region belong to various ethnic groups and the main economic sources are agriculture and fishery (Powell et al., 2011). Tien Hai district (Thai Binh Province) in the Red River Delta is traditionally known as the rice bowl of Vietnam and aquaculture farming is also common in this region (Osbeck et al., 
2010). The Red River Delta has a monsoon climate with a hot rainy season and warm dry season and typhoons are common in the region.

Wösten et al. (2003) investigated nutrient dynamics in mangrove areas of Red River delta under two realistic scenarios that help to understand the different interactions in the nutrient dynamics of the Red River Delta mangrove area: (1) increasing river discharge with constant or proportionally increasing river nutrient concentration and (2) increasing river discharge with decreasing river nutrient concentration. The first scenario resulted in increased nutrient concentration in the whole region and the second one in decreased nutrient concentration in the Delta.

Nearly $36 \%$ of the land area in the Red River Delta is below $2.5 \mathrm{~m}$ a.s.l. and sea dykes are necessary for flood prevention (Nguyen et al., 2010). Climate change predictions (increases in air temperature and reduction in precipitation) are more severe for the Red River Delta compared to the Mekong Delta, (Yu et al., 2010) and this makes mangroves in the Red River Delta more vulnerable compared with those in southern regions. In fact, the Red River Delta is predicted to be highly vulnerable to extreme weather events (IPCC, 2013). Furthermore, the illegal cutting of mangroves, difficulty in reforestation (mainly done using Kandelia candel) due to the lack of support from regional communities (as these reforestation programs do not have adequate compensation for reduced access to crabs and clams) result in a negative outlook for mangroves in the Red River Delta (Osbeck et al., 2010; Powell et al., 2011). However, it is admirable that there have been recent attempts to practice sustainable aquaculture in some regions (Tien Hai and Xuan Thuy nature reserves) in the Red River Delta (Pedersen and Nguyen, 1996).

\section{Socio-economic importance of mangrove vegetation in Vietnam}



against erosion and typhoons (which can significantly reduce dyke maintenance and coastal protection costs), provide goods and services such as wood for fuel and energy, filter pollutants and maintain water quality but they also play a vital role as nurseries and feeding habitat for a large number of coastal and marine species (Orchard et al., 2015a, 2016). $82 \%$ of marine products in Vietnam are from inshore areas, so mangroves also play a role in supporting the fishing industry by providing seed, feed and rearing grounds (Pomeroy et al., 2009). Vietnamese mangroves are known to provide a habitat for a wide range of species as well as supporting a high resource biomass encompassing shrimp, crab, and fish, (including Scylla paramamosain, Crassostrea gigas, Anadara granosa, and Meretrix lyrata) (Le Vay et al., 2001, McDonough et al., 2014) vital as a foodstuff for local communities supporting the livelihoods of coastal rural peoples (Orchard et al., 2015b). Ecosystem services provided mangrove vegetation in Vietnam include: habitat (fish, biodiversity) (Brander et al., 2012), fuel wood (e.g. charcoal), raw materials (such as timber/thatching) (Tri et al., 2000; MENR, 2002; FAO, 2007; Do and Bennett, 2005), coastal protection (Tri et al., 2000; Quartel et al., 2007; Bao, 2011), carbon storage (Tue et al., 2014), and salt production (FAO, 2007). Beck et al. (2018) suggest that mangroves in Vietnam protect more people (8 million) from flooding than in any other nation, and from a global list Vietnam is ranked fifth for the value of property (US\$ 7 billion) protected by mangroves.

In some provinces, mangrove forests fundamentally influence socio-economic conditions and provide important ecological services and livelihoods for local communities. According to Phan and Quan (2006), economically deprived communities in the north province from Ha Tinh to Quang Binh are now the direct beneficiaries of mangrove planting program when more than 16,000 ha of mangrove have been re- 
434 planted in 6 northern region provinces. Mangrove restoration efforts have been undertaken since the end of the Vietnam War, particularly in the Mekong Delta as a result of habitat destruction by Agent Orange. Between 1978 and 1999 35,000 ha of the original 40,000 ha of mangrove in Can Gio were restored, although survival rates in the 70's and 80's were low as a result of planting densities (Marchand, 2008). Similar examples can be found in $\mathrm{Ha}$ Tinh province, with survival rates around $40 \%$ (Erftemeijer and Lewis III, 1999), and Xan Thui and Tien Ha coastal reserves in north Vietnam where mangroves are fragmented and survival rates from restoration programmes are low (Seto and Fragkias, 2007). In many cases in Vietnam, restoration efforts were undertaken by school children or local communities providing additional income Vinh (2004), which in some cases resulted in limited project success. However, community involvement, particularly at the implementation stage, has in recent years been found to improve restoration success rates in Vietnam (Nguyen et al., 2016), and this combined with increased knowledge of geomorphic and ecological settings is improving restoration programme successes (Cuong et al., 2015, Balke and Friess, 2016). Examples for sustainable and unsustainable use of Can Gio mangrove forests are shown in Fig. 7.

Fig. 7: Sustainable and non-sustainable use of Can Gio mangrove forests. (a) and (b): use of edible Nypa fruticans, (c) shrimp ponds, (d) salt farms, (e) logging (Photos: Dr. Bijeesh Kozhikkodan Veettil)

Mangrove restoration programmes have been important in Vietnam due to the economic value these ecosystems provide to local communities. Phan and Quan (2006) identified that income from crab collecting provided a significant proportion $(16.1 \%$ - 
$22.8 \%$ ) of the total household income for communities near mangroves in the northern coast. Besides mangrove planting and timber collection, the local government also have policies for mangrove allocation for coastal protection and livelihood improvement such as in Kien Giang province from the south (Nguyen et al., 2017). These policies allow households to protect mangroves and also to earn for living directly from the mangrove forest which they plant and protect.

The Can Gio mangrove biosphere reserve forms a part of the Indo-West Pacific Biogeographical Region. The Southeast Asian sub-region is recognised as the biogeographical province supporting the most diverse mangroves in the World (Myers, 2000; Hughes, 2017). The Can Gio mangrove forest is an important source of income from associated aquatic resources for local communities such as timber, firewood, charcoal, tannin, food, medicinal but also the breeding ground for many species of marine organisms like shrimp, crab, fish, water and migratory birds as well as other economically terrestrial species of monkey, wild boars, boas etc. (Nguyen et al., 2000). Furthermore, Nguyen et al. (2000) also reported that this mangrove area consists of 77 mangrove species (35 true mangroves and 42 associates), which has economic and environmental importance in a coastal zone vulnerable to impacts from natural and anthropogenic driving forces.

Many mangroves suffered widespread degradation and losses such as the Can Gio mangrove forest during the Vietnam-war, and losses accelerated in the following decade as a result of conversion to aquaculture, deforestation and river damming (Son et al., 2015). More than $80 \%$ Vietnamese mangroves have been lost in the last 50 years for converting into aquaculture, especially shrimp, clam and other agriculture. According to Nga and Tinh (2008), mangrove-shrimp system is popularly practiced in the coastal provinces in the Mekong Delta where mangrove forest is approximately 186,277 ha, in 
which $161,277.5$ ha have been converted to shrimp ponds and other activities between 1953 and 1995. Nowadays, the main cause of mangrove loss in Vietnam is the conflict between economic development and conservation, particularly related to shrimp aquaculture (Joffre et al., 2015).

In 1999 mangrove forest rehabilitation planning in the coastal regions provinces from Tra Vinh to Ca Mau in Mekong delta was approved by the Prime Minister of Vietnam (Decision 116/1999 / QD -TTg). These coastal mangrove forests are classified into three main zones: (1) strict protection zone, (2) buffer zone and (3) economic zone. In the buffer zone, $60 \%$ of the area is used for afforestation and the remaining $40 \%$ is for aquaculture, agricultural cultivation and other activities. However, shrimp farming in the mangrove forests of the Mekong delta has been unsustainable due to unplanned development of shrimp farming areas, which has been identified as the main reason for the decrease in fish stocks, catch, increasing salt water intrusion and water pollution in coastal areas (Nga and Tinh, 2008).

The Vietnamese government tries to ensure the maintenance of ecosystem functions and processes underpinning local livelihoods; fostering the equitable distribution of ecosystem goods and services to encourage their sustainable use; and increasing the diversification of income opportunities to reduce pressure on mangrove resources (Orchard et al., 2016). However, Orchard et al. (2016) identified that the rapid growth of the aquaculture industry, combined with far-reaching land and market reforms, and local misappropriation of the benefits of these reforms, has undermined mangrove goods and services. A strong aquaculture industry has led to increased livelihood diversification at the community level, but growing specialisation at the household level. Orchard et al. (2016) also reported that female headed households were significantly more dependent on mangrove resources in all studied communes, and 
509 limited land use rights increased dependence on mangrove resources in communes with 510 a growing aquaculture industry.

511 Some coastal areas have suffered decreases in mangrove extent by $50-80 \%$ as a

512 result of conversion to shrimp farming, with a resultant loss of biodiversity and coastal 513 ecosystem functioning (Valiela et al., 2001; Manson et al., 2005; Hawkins et al., 2010;

514 Van et al., 2015), with an uncontrolled expansion in the number of farms, increased area 515 occupied and intensification of shrimp production. In particular, Ben Tre province in 516 southern Vietnam faces many environmental and societal challenges as a result of the 517 importance of aquaculture in the region (Khang, 2008).

518 Quinn et al. (2017) reported that mangroves in Vietnam are considered to be 519 under increasing pressure from climate change, coastal development, as well as 520 aquaculture. Population growth and changing political and economic processes have led 521 to land use changes and declining extent of mangroves. Additionally, almost all 522 mangroves have shrimp farms, and the rapid development of aquaculture is associated 523 with a significantly reduced and degraded mangrove (Orchard et al., 2016). Aquaculture 524 has been identified as the principal threat to mangrove systems in northern Vietnam 525 (Orchard et al., 2015b).

Although the benefits of mangrove forests are great in both economic and social 527 terms, the management, exploitation and protection of mangrove forests by the 528 government and local people in many provinces along the coast is often uncontrolled. 529 Many local people are poor and have a low awareness of the value of the mangroves 530 resulting in indiscriminate exploitation and destruction. Therefore, policy at all levels of 531 government and non-governmental organizations in Vietnam have a wide range of 532 activities to support coastal areas in mangrove management, prevent exploitation and 533 protection based on geographical characteristics of each locality. A solution suggested 
534 to enable appropriate mangrove management is the community - mangrove co535 management models such as has been implemented in the Nam Dinh and Mekong delta 536 provinces (Trung TC, unpublished document). The co-management model is designed

537 to implement reforestation and protection through a contract of ownership between local 538 government and local communities making local people responsible as forest co539 owners. This model allows local communities living near mangrove forests to acts as 540 guards and utilizes the forest for aquaculture, ecotourism, etc., they also have roles in 541 reforestation. In Vietnam this model is considered as a good choice to protect mangrove 542 vegetation whilst also helping local communities in their socio-economic development 543 (Trung TC, unpublished document; Thu Ha et al., 2012). areas in Vietnam

A number of papers were published recently on mapping and monitoring mangrove vegetation and ecosystem in Vietnam. These studies concentrated on the loss of mangrove vegetation due to shrimp farming and timber exploitation (e.g. Béland et al., 2006; Thu and Populus, 2007), reforestation (e.g. Tuan et al., 2014; Nguyen et al., 2016), and the assessment of ecosystem service value (e.g. Kuenzer and Tuan, 2013), etc. The vast majority of recent studies on Vietnamese mangrove forests are from the Mekong Delta, where more than $60 \%$ of Vietnam's mangrove forests are located. Mangrove species that are commonly found in Vietnamese coastlines and their geographical distribution are summarized in Table 1. 


\subsection{Role of remote sensing in monitoring mangrove ecosystems}

560

Remote sensing has been used worldwide for mapping and monitoring mangrove ecosystems (e.g. Green et al., 1998a, 1998b; Blasco et al., 1998, 2001; Giri et al., 2007; Everitt et al., 2008; Heumann, 2011; Kuenzer et al., 2011) and also in Vietnam (e.g. Tong et al., 2004; Béland et al., 2006; Seto and Fragkias, 2007; Thu and Populus, 2007; Kuenzer and Tuan, 2013; Vo et al., 2013, 2015; Thi et al., 2014; Hauser et al., 2017; Pham and Yoshino, 2017). A range of information can be obtained from remotely sensed data of mangrove ecosystems including habitat inventories, land cover changes, ecosystem evaluation and productivity assessment, water quality assessment, and disaster management (Kuenzer et al., 2011). Optical remote sensing approaches exploit the radiometric characteristics of mangrove species - i.e. the spectral discrimination of mangroves (Blasco et al., 1998). For details about spatial and spectral resolution of different satellite imagery, readers are requested to refer Purnamasayangsukasih et al. (2016).

Recently, there have been a large number of papers published on remote sensing applications for mapping and monitoring mangroves in Vietnam (Béland et al., 2006; Seto and Fragkias, 2007; Thu and Populus, 2007; Kuenzer and Tuan, 2013; Vo et al., 2013; Thi et al., 2014; Son et al., 2015; Pham and Yoshino, 2017; Hauser et al., 2017). Even though the full potential of available spaceborne imagery has not been exploited, results from the available literature are promising. Most of the mapping methods for optical and active satellite data and aerial photographs discussed - visual interpretation (e.g. Tong et al., 2004; Thu and Populus, 2007; Binh et al., 2008; Kautz et al., 2011; Thao et al., 2013; Van et al., 2015), on-screen digitizing (e.g. Binh et al., 2008; Thao et al., 2013), supervised (Tong et al., 2004; Binh et al., 2005; Tuan and Kuenzer, 2012; 
584 Kuenzer and Tuan, 2013; Nguyen et al., 2013; Luong et al., 2015; Pham and Yoshino, 585 2015; Van et al., 2015) and unsupervised (Béland et al., 2006; Hauser et al., 2017) 586 classification, band ratios (e.g. Thu and Populus, 2007; Lan et al., 2013), vegetation 587 indices (e.g.Tong et al., 2004; Binh et al., 2005; Seto and Fragkias, 2007; Thu and 588 Populus, 2007; Thi et al., 2014; Nardin et al., 2016), PCA (e.g. Binh et al., 2005), and 589 object-based image analysis (e.g.Vo et al., 2013; Son et al., 2015; Pham and Brabyn, 590 2017) - have been applied by researchers for mapping mangroves in Vietnam with the 591 exception of LiDAR, which has yet to be applied in this region. A summary of studies conducted in Vietnamese mangrove ecosystems using remote sensing and key methods used are given in Table 2.

594

Table 2: A summary of various remote sensing methods applied in Vietnam for monitoring and evaluating mangrove ecosystems

597

The spatio-temporal dynamics of land cover changes associated with mangroves is quite well studied in Vietnam using remote sensing. A number of recent studies have observed the fragmentation of mangrove vegetation or expansion of reforested 601 mangrove areas in Vietnam and particularly in Ca Mau Peninsula (e.g. Tong et al., 602 2004; Binh et al., 2005; Thi et al., 2014; Son et al., 2015; Van et al., 2015; Hauser et al., 2017; Pham and Brabyn, 2017), Can Gio Province (e.g. Binh et al., 2008; Tuan and Kuenzer, 2012; Luong et al., 2015) and Red River Delta (e.g. Seto and Fragkias, 2007; Lan et al., 2013; Thao et al., 2013). The effects of deforestation and afforestation on the 606 entire Vietnamese mangrove ecosystems needs to be analyzed effectively using remote 607 sensing datasets. Currently, a few regional studies exist that critically analyzed annual or decadal changes in mangrove areas. Hauser et al. (2017) conducted a study on Ca 
609 Mau mangrove forests (in the Ngoc Hien region) for the period 2004-2013 and observed

610 that there was a reduction in mangrove area between 2004 and 2009 whereas an

611 increase in mangrove areas due to afforestation was observed between 2009 and 2013,

612 even though net changes in mangrove area remained negative $(-0.34 \%)$. These were

613 caused by changes in aquaculture expansion, recent alterations in policy, reforestation,

614 international acknowledgement of protected areas, certification, integrated shrimp-

615 mangrove production systems and logging cycles (Hauser et al., 2017). Van et al.

616 (2015) also observed identical results in Ca Mau Peninsula using satellite images from

617 multiple sources. An increase in mangrove areas due to afforestation was also observed

618 in the Can Gio region between 2000-2011 using SPOT 4 and SPOT 5 imagery (Pham

619 and Brabyn, 2017). Pham and Brabyn (2017) observed that this increase in mangrove

620 areas was due to colonisation by Rhizophora apiculata whereas changes in above-

621 ground biomass due to Avicennia alba and Sonneratia alba were not spatially

622 consistent, probably due to soil accretion.

As Vietnamese mangroves are being lost due to extensive and unsustainable

624 shrimp farming, cost-effective methods for change detection are necessary and freely

625 available satellite imagery offers such a platform (e.g. Béland et al., 2006). On an

626 annual basis, conducting field surveys on aquaculture practices can be difficult as a

627 large area of mangrove ecosystems are utilized for this purpose every year. Recently,

628 Vo et al. (2015) attempted to estimate the potential of remote sensing data combined

629 with household surveys in evaluating mangrove ecosystem services (fisheries and

630 timber related products, carbon sequestration, and storm protection) in $\mathrm{Ca} \mathrm{Mau}$

631 province, where shrimp farming provides direct livelihood benefits to local

632 communities. A similar study was conducted by Kuenzer and Tuan (2013) near the Can

633 Gio Mangrove Biosphere Reserve as well using remote sensing techniques for species- 
634 level mapping of mangrove vegetation and combined this information with the results

635 of socio-economic household survey. They mapped 38,298 ha of mangrove vegetation

636 in 2011, including species level differentiation of Rhizophora and Avicennia areas, in

637 Can Gio using SPOT imagery. The same study observed that the local inhabitants lack

638 understanding of the value of natural resources if no direct income is generated from

639 such resources.

640 Optical remote sensing is being developed in Vietnam and VNREDSat 1

641 imagery, which is the first Vietnamese satellite, has been used for mangrove mapping in

642 Ca Mau province (Trang et al., 2016). However, the use of optical satellite imagery for

643 mangrove studies has limitations as a result cloud cover, common in tropical latitudes,

644 which limit the availability of good quality images. A limited number of studies (e.g.

645 Hoa et al., 2017) have been conducted in Vietnam using hyperspectral data for mapping

646 mangrove vegetation. For larger scale remote sensing applications, such as for creating

647 a spectral library commonly found mangrove species in Vietnam, hyperspectral data

648 will be necessary for future research. The availability of SAR imagery, which can be

649 used under any climate conditions, is limited in Vietnam. Future mangrove research

650 should be focussed on the application of LiDAR remote sensing techniques for

651 evaluating Vietnamese mangroves, which has not been applied in this region (Vo, 2013;

652 Luong et al., 2015). UAV-based images also offer a relatively cost effective method for

653 mangrove mapping with a high temporal coverage, something also currently lacking in

654 Vietnam.

655

656

9. Conservation and rehabilitation of mangrove ecosystems in Vietnam

657

Mangrove restoration has been given global attention in recent decades (Kairo et

658 al., 2001), predominantly due to substantial decreases in extent and diversity. It has 
659 been reported that $16 \%$ of mangrove species are threatened with global extinction 660 (Polidoro et al., 2010) and the situation in Vietnam is no exception. Mangrove 661 rehabilitation programmes are essential to reduce global and regional losses of 662 mangroves (Ellison, 2000a; Kairo et al., 2001; Lewis, 2005; Primavera and Esteban, 663 2008; Duncan et al., 2016). However, recent studies from several countries with 664 reforested mangroves reported very low survival rate of planted mangroves and in some 665 cases, total failure (e.g. Marchand, 2008; Primavera and Esteban, 2008; Van Loon et al., 666 2016) with two key reasons behind this failure reported: planting mangroves in the wrong location without consideration for hydrological and geomorphological characteristics, and the selection of inappropriate species for the site (Primavera and Esteban, 2008). In Can Gio mangroves in Vietnam it has also been reported that sediment physicochemical properties can also influence the success of mangrove reforestation (Oxmann et al., 2010).

673 large proportion of the settlements coexist in or near mangroves (Hawkins et al., 2010).

674 Vietnam has conducted more mangrove reforestation than any other country in the 675 world (Field, 2000) with restoration efforts starting in 1975 resulting in the 676 rehabilitation of nearly 53,000 ha by the early 1990 s (FAO, 2007). With the help of 677 various national and international NGOs, another 14,000 ha of mangrove reforestation 678 was completed in the following decade. In order to reduce mangrove losses as a result 679 of shrimp farming the authorities of Minh Hai province by establishing mixed shrimp 680 farming-mangrove forestry enterprises (SFMFEs) working in such a way that both 681 shrimp and mangroves (e.g. Rhizophora apiculata) are cultivated by farmers (Alongi et 682 al., 2000). 

undertaken a case-study measuring the impact and cost benefit of mangrove plantation in Vietnam, demonstrating the remarkable achievements of community based mangrove plantation projects by the Vietnam Red Cross (VNRC) that included direct economic and ecological benefits, protective benefits for private assets located outside the seadykes and in preparing to cope with disasters (IFRC, 2015). The VNRC had been conducting community-based mangrove plantation since 1994 (supported by the Danish Red Cross-DRC). VNRC mangrove plantation projects in Vietnam aim to attain both protective (e.g. shoreline and river bank protection, reduced disaster-induced material and non-material losses, reduced disaster-induced long-term indirect losses, shoreline stabilization, and reduced sea-dyke maintenance cost) as well as environmental (e.g. carbon sequestration, nutrient retention, sediment retention, biodiversity habitat, flood attenuation, wastewater treatment, and water supply and recharge) benefits (IFRC, Vietnam, 2015). The results of these projects by the Red Cross showed remarkable achievements in the protection of dykes since 1994. adaptation, particularly for mitigating the impact of sea level rise and coastal storms in purpose are Rhizophora stylosa, Kandelia candel, and Sonneratia caseolaris (Powell et al., 2011) as natural defences against landslides, coastal erosion and sea level rise 704 (McElwee et al., 2017). 
MFF Vietnam (2015) identified the incomplete and incoherent nature of policies,

709

710

711

712

713

714

715

716

717

718

719

720

721

722

723

724

725

726

727

728

729

730

731

732

laws and regulation governing mangroves in Vietnam as a substantial barrier to mangrove restoration success. The key reason for this has been identified as the administrative conflict between two ministries: Ministry of Natural Resources and Environment (MONRE) (responsible for coastal planning, land allocation, biodiversity conservation, aquatic ecosystem management and protection, and climate change) and Ministry of Agriculture and Rural development (MARD) (responsible for the management of forests, terrestrial and marine protected areas, fishing, aquaculture, sea dykes, and storm and flood control) (Swan, 2009a, 2009b). Before the MARD Proposal on Restoration and Development of Mangrove Forest in Coastal Areas for 2008-2015, Vietnamese government policies encouraged development and aquaculture in mangrove areas for the short-term economic gains (Hawkins et al., 2010). However, jurisdiction over mangroves is controlled by MONRE, MARD and the People's Committee at different levels (province, district and commune) and the weak collaboration between MARD and MONRE often creates uncertainty in mangrove management in Vietnam (MFF Vietnam, 2015).

Despite the intervention of national and international agencies for mangrove conservation in Vietnam, financial resources are still inadequate (Macintosh and Ashton, 2002). One of the potential ways to overcome the shortage of financial aid for mangrove conservation is via payments for ecosystem services (PES) from an ecosystem beneficiary to a land user for improving biomass health and diversity (Schmitt, 2009; Hawkins et al., 2010). Payments to mangrove managers for carbon sequestration is an example of such a PES. Similar methods can be adopted for storm and flood protection and aquaculture support (Hawkins et al., 2010). However, it is still uncertain that whether PES can compensate completely or partially for the profit lost by 
aquaculture managers. This compensation cost is in addition to the direct expense of planting mangroves, restoring degraded mangroves and maintaining a healthy mangrove ecosystem. Schmitt (2009) evaluated the possible advantages of co-management, in which government agencies and stakeholders share control of mangrove management in Vietnam. Its advantages include: effective protection of mangrove areas through zonation and ownership, secure and sustainable use of natural resources for improving livelihoods, lower workload for authorities and benefit sharing as a part of integrated coastal area management (Schmitt, 2009). Such a co-management scheme was established in Soc Trang province in southern Vietnam between 2007 and 2010 to promote co-management of coastal zone between resource users and the government and has provided promising results (Lloyd, 2010; Schmitt et al., 2013). However, it has been observed that co-management method is only successful with political support at all levels (province to communities) and with a good agreement among the stakeholders (Lloyd, 2010).

Further challenges to mangrove survival and restoration, particularly in rapidly eroding areas or near sluice gates, are similar to elsewhere in the world (Hawkins et al., 2010). Additional expenses may be expected for building breakwater barriers or fencing in such cases. Orchard (2014) reported that financial aid from the government and NGOs for mangrove restoration and conservation projects typically only reaches a few employees working for the government and their associates and many marginalised households received no benefits from such projects.

\subsection{Examples of rehabilitation and reforestation of mangrove areas in Vietnam}

Can Gio Mangroves: Mangrove restoration in Can Gio has been acknowledged as a success (Fig. 8), due to favourable hydrological and geomorphological conditions (Van 
Loon et al., 2016) and the fact that the planted species have mixed with naturally regenerated species (Marchand, 2008). The key species used for mangrove restoration after the Vietnam War since 1978 in Can Gio is Rhizophora apiculata (Nam and Sinh, 2015). Other species planted include Nypa fruticans, Ceriops tagal and Rhizophora mucronata (Hong, 2001; Marchand, 2008). Can Gio was designated a coastal protection forest by the Ministerial Council Decision 173 CT in 1991 (Tuan and Kuenzer, 2012; Nam et al., 2014). Furthermore, in order to protect the restored mangroves from being converted to shrimp ponds, this region was declared as a Biosphere Reserve in 2000 (Van Loon et al., 2016). The three key management objectives of Can Gio Mangrove Biosphere Reserve are: biodiversity conservation, environmentally-sound social, cultural and economic development, and mangrove-related training, research and education (Tuan et al., 2002; Nam et al., 2014). Cornier-Salem et al. (2017) highlighted the necessity of interdisciplinary studies to better understand the contribution of mangroves to local communities based on a case study on Can Gio Mangroves.

Fig. 8: Reforested and regenerated mangroves in Can Gio Mangrove Biosphere Reserve (Photo: Dr. Bijeesh Veettil)

Ca Mau Peninsula: Several mangrove rehabilitation projects funded by foreign agencies were established in Ca Mau in the 1990s (Benthem et al., 1999) and the World Bank Coastal Wetlands Protection and Development Programme planted about 25,262 ha of mangroves in Ca Mau (MAB Vietnam, 2008; Van et al., 2015). There are also several naturally regenerated mangrove areas near shrimp ponds in the $\mathrm{Ca} \mathrm{Mau}$ Peninsula consisting mainly of Avicennia spp. and Rhizophora spp. (Van Loon et al., 2016). Reforested areas were mainly planted with Rhizophora spp., which is 
783

784

785

786

787

788

789

790

791

792

793

794

795

796

797

798

799

800

801

802

803

804

805

806

807

predominantly responsible for the net increase in mangrove area in Ca Mau between 1992 and 2004 (Van et al., 2015). In order to protect different mangrove species in Ca Mau, Mui Ca Mau National Park has been established on the south-western tip of the peninsula in 2003 (Van Loon et al., 2016). Some mangrove areas of Ca Mau Peninsula have been designated as a UNESCO International Biosphere Reserve in 2009 and this was designated as a Ramsar site in 2013 (Van et al., 2015). In a recent cost-benefit analysis of climate adaptation, Nguyen (2015) estimated that the total net benefit of mangroves in Ca Mau is US\$ 1,692.50 ha/yr, including labour costs. Restoration measures taken for Ca Mau mangroves, which constitute more than $50 \%$ of Vietnam's total mangroves (Jhaveri et al., 2018), still need improvement as intensive aquaculture has severely affected mangroves in the area and the restoration process is slow (Van et al., 2015).

Kien Giang Biosphere Reserve: This Biosphere Reserve, including the dwarf forest areas of Phu Quoc Island, was established in 2006 for the conservation of its high biodiversity. The decision No. 25/2011/QD-UNBD of the Kien Giang People's Committee on Regulation for Mangrove Management and Development in Kien Giang Province and Provincial Mangrove Rehabilitation plan for 2011-2020 period is one of the key management strategies for mangrove conservation in this region (Cuong and Brown, 2013). Unlike Can Gio or Ca Mau mangroves, the key pressures on Kien Giang mangroves is coastal erosion due to the particular low-lying geomorphology and ocean currents induced by strong winds (Russel, 2012). Cuong et al. (2015) identified the use of Melaleuca fences in rapidly eroding areas of Kien Giang as a successful soft coastal engineering approach. Nguyen et al. (2016) also observed that the mangrove restoration project in the Vam Ray region of Kien Giang, using different types of Melaleuca fences 
resulted in the gradual expansion of mangrove areas although results were poorly

809 documented as a result of insufficient local involvement. Based on case studies on Kien

810 Giang mangroves, some researchers (e.g. Nguyen et al., 2015, 2016) suggest the use of

811 a combination of Melaleuca fences together with reforested mangroves for efficient

812 coastal protection. Key constraints on achieving mangrove reforestation goals in Kien

813 Giang have been identified as: policies, implementation and proper law enforcement together with inadequate harvest practices in critically eroding areas (Nguyen et al., 2017).

816

Red River Delta and adjacent mangroves: Mangrove restoration in Red River Delta was started by the Red Cross in the 1990s as a method for shore protection against storms (Marchand, 2008). A Japanese NGO named ACTMANG (Action for Mangrove Reforestation) started mangrove planting projects in three districts (Thai Thui, Tien Lang, and Tinh Gio) and a total of 1,100 ha has now been planted (Marchand, 2008). The main species planted in these regions were Kandelia candel and Sonneratia caseolaris (Kogo and Kogo, 2000). Community-based mangrove rehabilitation programmes, funded mainly by the Japanese organizations in the northern coast of Vietnam has been found to be successful in some areas with the exception of regions with shrimp ponds and the replanting of mangroves in abandoned shrimp ponds has been identified as necessary (Pham and Yoshino, 2016b). However, Osbeck et al.

828 (2010) observed that the local community was not adequately compensated for reduced 829 access to crabs and clams in the Red River Delta as these regions were given with a special protective status. 
Climate change has been noted as being one of the principle threats to mangrove ecosystems as a result of a range of factors including increases in atmospheric $\mathrm{CO}_{2}$, increases in temperature, increased storminess, sea level rise, ocean currents and an altered precipitation regime, with sea level rise being noted as the primary threat (Ward et al., 2016b). In Vietnam, mangroves have already been designated as critically degraded as a result of a combination of factors including war and resultant habitat destruction, poor management, and conversion to aquaculture, which combined with climate change has the potential to result in a further decrease in area and habitat quality and resultant losses of ecosystem services (Duke et al., 2007; DasGupta and Shaw, 2013; Alongi, 2015).

Rates of local sea level change in vegetated coastal areas are controlled by a range of factors including subsidence/uplift, sediment accumulation, eustatic sea level changes, and storm intensity and frequency (Ward et al., 2016b). Several studies have investigated the impacts of sea level rise on mangroves in Vietnam, predominantly focusing on the two principal areas, the Mekong and Red River deltas in the south and north respectively. Tide gauge data from Vietnam show that sea level rise between 1993 and 2008 was about $3 \mathrm{~mm} / \mathrm{yr}$ (MONRE, 2009), broadly in line with global rates of sea level rise $(3.2 \pm 0 . \mathrm{mm} / \mathrm{yr})$ derived from satellite data (IPCC, 2013). However, in both

852 the Mekong, and to a lesser extent, Red River deltas this is likely to be exacerbated by 853 decreases in sediment discharge as a result of damming in the upper reaches for hydropower and sediment mining (Minh Duc et al., 2012; Van Manh et al., 2015; Allison et al., 2017b; Schmitt et al., 2017). Van Manh et al. (2015) suggest that the combined effects of hydropower development, climate change, sea level rise and deltaic 
857 subsidence could decrease overall sedimentation by $40 \%$. Land subsidence is also likely 858 to compound the impacts of sea level rise although this is geographically variable (Red 859 River delta $0.9 \mathrm{~mm} / \mathrm{yr}$, Neumann et al., 2015; Mekong delta 10-40 mm/yr, Erban et al., 860 2014) and this is exacerbated in the Mekong delta by groundwater extraction (Erban et 861 al., 2014), although this may be somewhat compensated within the mangroves by the 862 promotion of vertical accretion by roots as has been seen in other areas (Krauss et al., 863 2014) or through incomplete in-situ decay of organic matter (Kirwan and Megonigal, 2013). Nguyen and Woodroffe (2016) suggest that the Kien Gang coast within the western part of the Mekong delta is likely to be highly vulnerable to sea level rise in part due to the distance from the principal sediment carrying distributaries. However, 867 there are suggestions that mangroves in Asia may be more resilient to sea level rise compared to other regions due to high plant species diversity (Ward et al., 2016b) that cause greater interspecific facilitation (Huxham et al., 2010) and increased belowground root production (Lang'at et al., 2014). Sea level rise is also likely to have an increased impact in areas with shallow coastal waters as a result of tidal regime 872 deformation mechanisms including: increasing the phase speed and direction of the tidal 873 wave, and decreasing tidal friction resulting in an increase in the frequency of flooding 874 in intertidal areas (Nhan, 2016), potentially influencing areas as far inland as Can Tho 875 City $80 \mathrm{~km}$ inland (Takagi et al., 2014). In light of the potential impacts of sea level rise and increases in wave energy as a result of climate change it is necessary to consider 877 how management could mitigate these effects. The temporary installation of bamboo 878 breakwaters at mangrove restoration sites has been shown to increase sediment 879 accumulation as a result decreases in wave energy behind these structures (Schmitt et 880 al., 2013). Cuc et al. (2015) have shown in restored mangrove plots in the Mekong delta that $70 \%$ plant cover decreases wave heights by $60 \%$ compared with $40 \%$ in natural 
regenerated forest, and as low as $35 \%$ plant cover could reduce wave heights buy a similar amount as natural regenerated forests ( $42 \%$ decrease), decreasing the possibility of erosion and potentially stimulating sediment accumulation. Documented losses of mangroves set the stage for a range of socio-economic impacts linked to climate change including saline water intrusion impacting rice production in two of the world largest rice producing areas (Red River and Mekong deltas), storm surge related damage to infrastructure (Esteban et al., 2014) and flooding (Powell et al., 2011), suggesting that mangrove restoration as a soft defence option is an important strategic option for coastal management. In addition to these ecosystem services mangroves provide an important role in sequestering and storing carbon, mitigating climate change, predominantly 892 within soils, although also as above and below-ground biomass (Pendleton et al., 2012).

893 Carbon can be derived from a range of sources including terrestrial sediments, autochthonous production and marine sources including phytoplankton (Kelleway et al., 2018). Tue et al. (2012a) found that the principal sources of carbon stored in mangroves in the Xuan Thuy National Park (Red River delta) were in situ organic production

897 followed by marine phytoplankton with mangrove derived organic matter dominant in 898 the water column at mid-low tide and enhanced during the rainy season, and marine 899 phytoplankton at its highest levels at high tide (Tue et al., 2012b). Typically newly restored mangroves have relatively low levels of carbon stored (Cuc et al., 2009),

901 However, over time, both natural-state, naturally regenerated, and restored mangroves 902 have been found to store similar and large amounts of carbon in Vietnam (765-1026 $903 \mathrm{MgC} / \mathrm{ha}$ ) (Tue et al., 2014; Dung et al., 2016; Nam et al., 2016), about mid-range 904 compared to global estimates (Pendleton et al., 2012). Due to the area that mangroves cover in Vietnam these are globally significant figures. 

during the wet rainy season (May-October) has been observed to be high over the last five decades (Schmidt-Thomé et al., 2015). The increase in precipitation was between $5 \%$ and $10 \%$ in the northern region whereas the maximum increase in precipitation reached up to $20 \%$ in southern Vietnam (Schmidt-Thomé et al., 2015).

Fig. 9: Changes in the air temperature (in ${ }^{\circ} \mathrm{C}$ ) and precipitation (in \%) during the last 50 years in different climate regions of Vietnam (Source: MONRE, 2012a, 2012b) (Fig. 1), where temperatures vary little, rarely outside a $16-38^{\circ} \mathrm{C}$ range. A gradual rise in temperature may result in the expansion of mangroves towards higher latitudes (e.g. Cavanaugh et al., 2014, 2018, Osland et al., 2017). However, what will be the impact of rising temperatures at places where the maximum temperature threshold for mangrove ecosystem already met (e.g. in the tropics, where temperatures are already high) is unknown. Some studies have suggested that there may be adverse effects on physiological activities such as transpiration and photosynthesis (Hong, 1991), this is unlikely to be the case for Vietnam as any increase is unlikely to exceed the threshold for photosynthesis for mangroves $\left(38-40^{\circ} \mathrm{C}\right.$, Clough et al., 1982). However, there may be changes in plant community composition particularly in northern areas of the country where temperature increases are predicted to be highest (Fig. 3), perhaps increasing species diversity similar to that found in South Vietnam. Adequate rainfall is another factor necessary for normal mangrove physiological functioning (Gilman et al., 2008). Reduced precipitation decreases freshwater input to mangrove systems and can result in greater rates of evaporation, which leads to increases in soil salinity, which in turn 
931 results in decreased seedling survival, productivity and growth rates, productivity, zonal

932 diversity, and area of mangroves (Duke et al., 1998, Ellison, 2000b). The southwest

933 monsoon from the Indian Ocean brings heavy rainfall to Vietnamese coasts and nurtures

934 mangrove vegetation in this region. However, in the last 50 years there have been

935 decreases in rainfall, which are likely to have an impact on plant species as well as on

936 community function. Storms and cyclones also impact on the Vietnamese coastline, and

937 are likely to increase in strength globally over the $21^{\text {st }}$ century (IPCC, 2014). There have

938 been suggestions that there has been an increase in the number of very strong tropical

939 cyclones and an increase in the length of the storm season, although the number of

940 tropical cyclones making landfall in Vietnam has exhibited no changing pattern

941 (Nguyên and Truong, 2012). Even though the resilience of mangroves towards storms

942 and cyclones can be species-specific, storms can potentially cause damage through

943 defoliation and tree mortality for all species (Gilman et al., 2008). Cold winds due to the

944 northeast monsoon from the East Sea during the winter reduce the air temperature in

945 northern Vietnam, thereby limiting the growth of mangroves (Hong and San, 1993).

946 Hong (1984) reported that northeast monsoon caused increase in salinity of inland rivers

947 in a few rivers in Ben Tre province, which resulted in the inland migration of

948 halophytes (e.g. Avicennia alba, Xylocarpus granatum).

949 Hydrological factors (tides, ocean and freshwater water currents, salinity and

950 erosion) that influence mangrove vegetation in Vietnam cannot be considered separately

951 from climate influence as these factors are extremely sensitive to climate change. For

952 example, tides can be exacerbated by climatic factors such as rainfall and wind

953 (Schmidt-Thomé et al., 2015). The tidal range varies along the Vietnamese coastline

954 with macro-, meso, and micro-tidal regimes found. It has been reported that mangroves

955 in southern Vietnam affected by semi-diurnal tides develop better than mangrove forests 
in the north of the country, where the coastal region is affected by diurnal tides (Hong and San, 1993). High tidal amplitude and strong tide currents cause erosion and minimize mangrove propagation - this observation is important in the context of sea level rise. On the other hand, very low tidal amplitude does not help in transporting seeds and sediments (e.g. northern Ca Mau). Sea level rise adversely affects mangroves due to changes in duration and frequency of inundation and alterations in salinity levels (Friess et al., 2012). In fact, Alongi (2008) identified Vietnamese coasts as one of the hotspots vulnerable to a future sea level rise due to a low tidal range and lower sediment output (excluding the Mekong and Red River deltas.

\section{Conclusions}

Mangrove forests are located throughout the coast of Vietnam, although the best examples of these have evolved in the Mekong, and to a lesser extent, Red River Deltas as a result of the favourable geomorphology, hydrology and sedimentary environment.

Over $70 \%$ of mangroves in Vietnam occur in the South, mostly located along the Mekong River and its delta, although these were largely degraded or destroyed during the Vietnam War due to the application of herbicides and further degradation has occurred due to unplanned shrimp farming and illegal logging. A historical lack of sufficient regulatory mechanisms for the protection of mangroves has also contributed to the loss of such ecosystems in Vietnam. Mangroves in Vietnam support high species diversity as well as providing a range of ecosystem services. Of these ecosystem services, fisheries and aquaculture are considered to be vital to local economies with $82 \%$ of marine products in the country derived from inshore areas. Important mangrove associate species include Scylla paramamosain, Crassostrea gigas, Anadara granosa, and Meretrix lyrata, an important source of food for coastal rural communities. 
981 However, uncontrolled aquaculture development has resulted in compounding losses in mangrove area cover in Vietnam. In response to the recorded losses in mangrove extent, there have been many restoration and rehabilitation schemes implemented in Vietnam been noted as: lack of appropriate knowledge of required sedimentary and hydrological environment, poor choice of species, incorrect planting densities, lack of inclusion of local stakeholders and administrative conflict at a governmental level. There have neen some notable successful restoration rehabilitation programmes including those within the Can Gio Mangrove Biosphere Reserve, the Ca Mau Peninsula, the Kien Gang Biosphere Reserve and the Red River Delta districts Thai Thui, Tien Lang and Tinh

Gio. Financial resources for compensation mangrove conservation are limited and this has been noted as a barrier to successful mangrove conservation. However, various comanagement schemes have been implemented to reduce the impact of conservation of local populations and improve the sense of ownership and responsibility.

In recent years the number of studies and published papers on mangrove research in Vietnam has increased significantly. Most of these studies were from Can

997 Gio mangrove biosphere reserve, Ca Mau Peninsula and Red River Delta. Remote 998 sensing has provided a novel cost effective methodology for mapping and evaluation of mangrove forests in Vietnam. However, despite the use of various optical and active satellite data and various mapping algorithms, the full scope of remote sensing LiDAR data, both of which have been proven to be efficient in forest research. of aquaculture, logging, sea level rise and alterations to sediment budgets as a result of 
1006

1007

1008

1009

1010

1011

1012

1013

1014

1015

1016

1017

1018

1019

1020

1021

1022

1023

1024

1025

1026

damming, particularly in the Mekong, and to a lesser extent, Red River deltas. Sea level rise is likely to be exacerbated in the Mekong Delta as a result of land subsidence, partly due to ground water extraction. It is difficult to predict the future state of mangroves in Vietnam, predominantly due to the patchy data available, including a detailed knowledge of the extent of mangrove cover in the country, the current environmental status, and species distribution and abundance within different mangrove forests. Developing a combined database for Vietnamese mangroves could have administrative as well as scientific advantages. The Global Mangrove Database Information System (GLOMIS), implemented by the International Society for Mangrove Ecosystems (ISME) and funded by the International Tropical Timber Organisation (ITTO), conducts research and training activities (formerly commissioned by UNDP/UNESCO) concerning the management of mangrove ecosystems (Baba et al. 2004). GLOMIS collects information, including satellite imagery, within four regional centres (Brazil, Fiji, Ghana and Malaysia) and these are disseminated worldwide (from the headquarters in Japan). Even though still in its development stage, GLOMIS has perspectives for collecting multi-temporal information at both global and regional scales that can enhance research on mangrove ecosystems. Researchers can contribute their results derived from remote sensing datasets and improve the quality of research in this field. From a regional point of view, whilst better than many other areas of the globe, mangrove research using remote sensing in Vietnam is still in its infancy compared to regions such as Australia, USA, Brazil and Indonesia. 